\title{
黑枸杞与石墨烯纳米片在染料敏化太阳能电池中的应用
}

\author{
谢寿东 ${ }^{1}$, 王 刚 ${ }^{2}$, 陈慧媛 ${ }^{1}$ ，林 红 ${ }^{1,3}$ ，闫志男 ${ }^{1}$ ，张 慧 ${ }^{1}$
}

(1. 青海大学 化工学院, 西宁 810016; 2. 青海民族大学 物理与电子信息工程学院, 西宁 810007 ; 清华大学 材 料学院, 新型陶瓷与精细工艺国家重点实验室, 北京 100084)

摘 要: 从高原黑枸杞中提取染料, 利用紫外-可见吸收光谱和循环伏安方法研究不同 $\mathrm{pH}$ 染料的光电化学性能, 确 定染料最佳 $\mathrm{pH}$ 。以石墨烯为原料制备不同含量乙基纤维素(EC)的石墨烯纳米片(GNs)对电极，用电化学阻抗、循环 伏安、塔菲尔极化曲线研究不同 $\mathrm{EC}$ 含量对 GNs 对电极电催化性能的影响。以最佳 $\mathrm{pH}$ 染料为光敏剂, 不同含量 $\mathrm{EC}$ 的 GNs 为对电极组装染料敏化太阳能电池在模拟太阳光下测试光电转换效率。结果表明, $\mathrm{EC}$ 含量为 $10 \mathrm{wt} \%$ 时, GNs 对电极有良好的电催化性。光电测试 $\mathrm{EC}$ 含量为 $10 \mathrm{wt} \%$ 的 GNs 对电极光电转换效率为 $0.92 \%$, 接近 $\mathrm{Pt}$ 对电极 $(0.99 \%)$ 。

关 键 词: 染料敏化太阳能电池; 黑枸杞; 石墨烯纳米片对电极; 光电转换效率

中图分类号: TQ174 文献标识码: A

\section{Lycium Ruthenicum Murray and Graphene Nanoplates for Dye Sensitized Solar Cell}

\author{
XIE Shou-Dong ${ }^{1}$, WANG Gang ${ }^{2}$, CHEN Hui-Yuan ${ }^{1}$, LIN Hong $^{1,3}$, YAN Zhi-Nan ${ }^{1}$, ZHANG Hui ${ }^{1}$ \\ (1. College of Chemical Engineering, Qinghai University, Xining 810016, China; 2. College of Physics and Electronic Engineering, \\ Qinghai Nationalities University, Xining 810007, China; 3. State Key Laboratory of New Ceramics \& Fine Processing, School \\ of Materials Science and Engineering, Tsinghua University, Beijing 100084, China)
}

\begin{abstract}
The natural dye was extracted from Lycium Ruthenicum Murray which was cultivated in Tibetan Plateau. The UV-Vis absorption spectra and cyclic voltammetry were used to characterize the dyes and confirm the optimal $\mathrm{pH}$ of the dye solutions. The influence of different contents of ethyl cellulose(EC) on the performance of electric catalytic of graphene nanoplates(GNs) counter electrode were investigated through electrochemical impedance spectra, cyclic voltammetry and Tafel polarization curve. DSCs were assembled by using the natural pigments with optimal $\mathrm{pH}$ as sensitizers and the GNs counter electrode with different contents of EC as counter electrode. It was found that the GNs counter electrode with $10 \mathrm{wt} \% \mathrm{EC}$ achieved the best performance of electric catalytic. The highest power conversion efficiency of the GNs counter electrode with $10 \mathrm{wt} \%$ EC was $0.92 \%$, close to that of Pt counter electrode $(0.99 \%)$.
\end{abstract}

Key words: dye-sensitized solar cell; Lycium Ruthenicum Murray; graphene nanoplates counter electrode; photoelectric conversion efficiency

收稿日期: 2016-03-21; 收到修改稿日期：2016-05-10

基金项目：国家自然科学基金(51362025); 清华大学新型陶瓷与精细工艺国家重点实验室开放课题(KF201406); 青海省昆 仑学者计划; 教育部春晖计划(Z201539)

National Natural Science Foundation of China(51362025); Key Laboratory of New Ceramics and Fine Processing, Tsinghua University(KF201406); Kunlun Scholar Program of Qinghai; Parental affection plan project(Z201539) 
随着对可再生能源的开发和利用, 人们对太阳 能的需求也越来越高, 其中染料敏化太阳能电池 (Dye-Sensitized Solar Cells, 简称 DSSCs) 以其无污 染、制备成本低和良好的转化效率等特点得到了广 泛重视 ${ }^{[1-3]}$ 。DSSCs 主要由 $\mathrm{TiO}_{2}$ 多孔薄膜、染料敏 化剂、电解质和对电极组成。染料敏化剂在电池中 起着光吸收的作用, 目前除了采用效率较高且性能 稳定的无机染料, 有机染料也得到了广泛应用, 但 由于有机合成染料制备成本高, 并且污染环境, 因 从植物中提取的天然有机染料备受关注 ${ }^{[4-6]}$ 。青藏高 原日照时间长, 高海拔, 常年受强紫外照射, 因此 研发高原天然有机染料具有突出优势 ${ }^{[7]}$ 。其中, 黑枸 杞常年生长干旱地区, 果实含有丰富花青素, 是最 具代表性的高原植物 ${ }^{[8]}$ 。

在 DSSCs 中, 对电极主要收集和传输电子。目 前, 主要用 $\mathrm{Pt}$ 对电极来组装电池, 但是在大面积电池 中生产成本较高, 长时间在电解液中易被腐蚀 ${ }^{[9-10]}$, 因此开发稳定低成本的对电极材料是 DSSCs 研究的 重点。石墨烯作为典型的二维碳材料 ${ }^{[11]}$, 由其制备得 到的石墨烯纳米片(GNs)因结构多样性、高强度、高 比表面积而成为新能源材料的研究热点 ${ }^{[12-16]}$ 。

本工作从黑枸杞中提取和提纯染料, 分析染料 HOMO、LUMO 能级, 并制备不同含量乙基纤维素 (EC)的 GNs 对电极, 再以黑枸杞染料为敏化剂, 与 GNs 对电极组装成电池, 测试光电化学性能。

\section{1 实验方法}

\section{1 染料制备}

将从海拔 3000 多米的青海省海西州采摘的黑 枸杞阴干后, 在鼓风干燥箱中 $50^{\circ} \mathrm{C}$ 干燥 $30 \mathrm{~min}$ 。烘 干的黑枸杞在玛瑙研针中研磨成粉, 放入无水乙醇 溶液中, 在 $25^{\circ} \mathrm{C}$ 下遮光放置 $24 \mathrm{~h}$ 后超声 $20 \mathrm{~min}$, 反 复超声提取两次。提取液经离心分离后, 取其上清 液用乙酸乙酯和石油醚进行少量多次萃取, 并用蒸 馏水和石油醚进行反萃取, 萃取液真空浓缩。得到 的浓缩液在薄层板上薄层分析, 多次试验后, 以石 油醚:乙醚(体积比 $5: 2$ )为展开剂效果最佳。用石油 醚: 乙醚(体积比 $5: 2$ ) 作为洗脱剂, 聚酰胺干法装柱, 对浓缩液进行柱色谱分离, 得到黑枸杞染料。

\section{2 光阳极的制备}

根据文献[15]方法制备 $\mathrm{TiO}_{2}$ 浆料: 按质量比为 $\mathrm{TiO}_{2}: 10 \% \mathrm{EC}$ : 松油醇=18：9：73 分别称取原料, 首先将 $\mathrm{TiO}_{2}$ 放入烧杯超声 $10 \mathrm{~min}$ 分散均匀, 再加入 $10 \% \mathrm{EC}$, 最后加入松油醇, 超声分散均匀, 旋转蒸
干乙醇, 在三辊机上混合 $15 \mathrm{~min}$, 得到 $\mathrm{TiO}_{2}$ 浆料。

将 $\mathrm{TiO}_{2}$ 浆料均匀涂抹在导电玻璃上, 在马弗炉中程 序加温 $\left(325^{\circ} \mathrm{C}\right.$ 加热 $5 \mathrm{~min}, 375^{\circ} \mathrm{C}$ 加热 $5 \mathrm{~min}, 450^{\circ} \mathrm{C}$ 加热 $15 \mathrm{~min}, 500^{\circ} \mathrm{C}$ 加热 $30 \mathrm{~min}$ ), 得到 $\mathrm{TiO}_{2}$ 电极, 电 极浸泡染料 $12 \mathrm{~h}$ 得到光阳极。

\section{3 对电极制备}

按文献[16]制备氧化石墨烯, 将 $0.5 \mathrm{~g}$ 氧化石墨 在超纯水中超声分散 $30 \mathrm{~min}$ 后加入 $15 \mathrm{~mL}$ 水合肼并 在 $80^{\circ} \mathrm{C}$ 下反应 $24 \mathrm{~h}$, 最后在 $80^{\circ} \mathrm{C}$ 下干燥 $24 \mathrm{~h}$ 得到还 原石墨烯纳米片。将石墨烯纳米片在不同含量 $(5 \mathrm{wt} \% 、 10 \mathrm{wt} \% 、 15 \mathrm{wt} \%) \mathrm{EC}$ 的异丙醇溶液中超声分 散均匀, 再加入松油醇, 超声分散 $10 \mathrm{~min}$, 得到的 石墨烯纳米片(GNs)刮涂在 $\mathrm{FTO}$ 上, 在 $400^{\circ} \mathrm{C}$ 下烧结 $15 \mathrm{~min}$ 得到不同含量 $\mathrm{EC}$ 的 GNs 对电极。

将 $\mathrm{H}_{2} \mathrm{PtCl}_{6}$ 异丙醇溶液滴到导电玻璃, 并在 $450^{\circ} \mathrm{C}$ 下加热 $30 \mathrm{~min}$ 得到 $\mathrm{Pt}$ 对电极。

\section{4 电池组装}

光阳极和对电极用平口夹固定组装电池, 电解液 为 $0.1 \mathrm{~mol} / \mathrm{L}$ 碘化锂 $(\mathrm{LiI})+25 \mathrm{mmol} / \mathrm{L}$ 碘 $\left(\mathrm{I}_{2}\right)+0.6 \mathrm{~mol} / \mathrm{L}$ 1,2-二甲基-3-丙基咪唑碘化物 (1,2-dimethyl-3-propylimidazolium iodide,DMPII) $+0.5 \mathrm{~mol} / \mathrm{L}$ 4-叔丁基 吡啶(4-tert-butylpyridine,TBP)的无水乙腈溶液。

\section{5 表征测试}

利用紫外-可见吸收光谱(UV-4802)对染料进行 光谱吸收测试, 电化学工作站(HR-Zennium)对染料 进行电化学性能测试, 计算染料氧化还原电位。用 SEM(JEM-6610LV)观察对电极形貌, 利用电化学工 作站测试对电极电化学阻抗, 循环伏安曲线, 塔菲 尔极化曲线, 测试电极催化性能。采用太阳光模拟 器(1000 W91192)和数字源表(2400 IV,Keithley)对电 池进行光电性能测试, 光强为 $100 \mathrm{~mW} / \mathrm{cm}^{2}$ 。

\section{2 结果与讨论}

\section{1 染料表征}

图 1 是不同 $\mathrm{pH}$ 黑枸杞染料的紫外-可见吸收光 谱, 在 400 650 nm 范围, $\mathrm{pH}=3$ 的染料吸收范围最宽, 在 $550 \mathrm{~nm}$ 处, $\mathrm{pH}=1$ 的染料吸光度最大。 $\mathrm{pH}=1 、 3$ 、 $5 、 7$ 的染料吸收截止波长分别为 $623 、 636 、 614$ 、 $608 \mathrm{~nm}$, 根据染料的吸收截止波长, 由 $E_{\mathrm{g}}=1240$ / $\lambda_{0}\left(\lambda_{0}\right.$ 为染料吸收截止波长)计算得到染料的禁带宽度。

图 2 是不同 $\mathrm{pH}$ 黑枸杞染料的循环伏安曲线, 测 试以铂丝为工作电极, 铂片为对电极, $\mathrm{Ag} / \mathrm{Ag}^{+}$电极为 参比电极, $10 \mathrm{mmol} / \mathrm{L} \mathrm{LiI}+0.1 \mathrm{mmol} / \mathrm{L} \mathrm{I}_{2}+0.1 \mathrm{~mol} / \mathrm{L}$ $\mathrm{LiCIO}_{4}$ 乙腈溶液为电解液。从图 2 可知, 黑枸杞染 


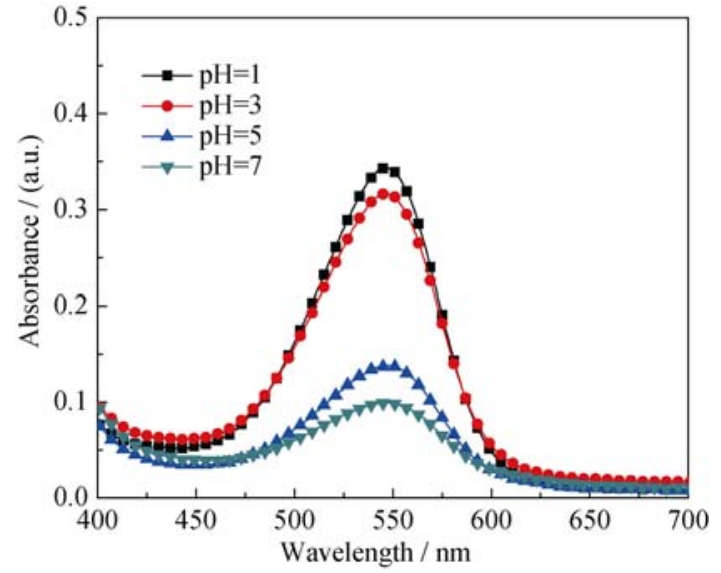

图 1 不同 $\mathrm{pH}$ 黑枸杞染料的紫外-可见吸收光谱图

Fig. 1 UV-Vis absorption spectra of lycium pigment from ruthenicum murray under different $\mathrm{pH}$

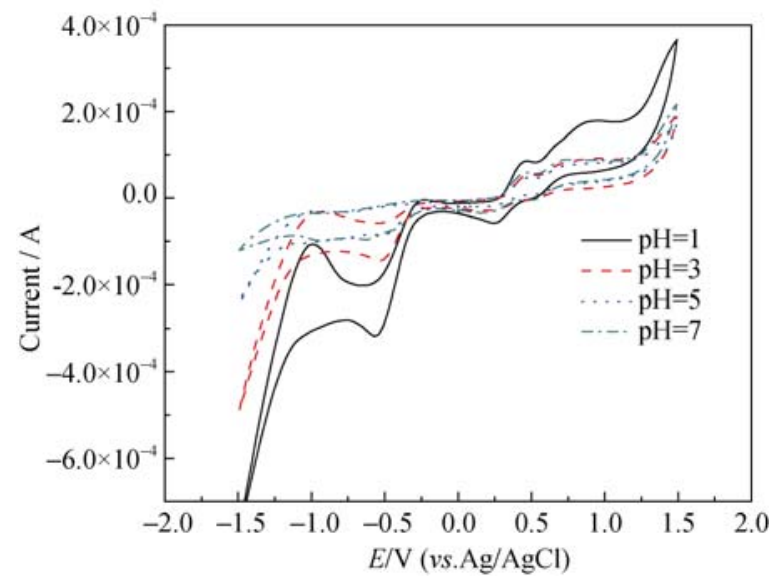

图 2 不同 $\mathrm{pH}$ 染料的循环伏安曲线

Fig. 2 Cyclic voltammogram curves of pigment from $L y$ cium ruthenicum Murray under different $\mathrm{pH}$

料在 $\mathrm{pH}=1 、 3 、 5 、 7$ 时氧化还原电位分别为 1.12 、 1.15、1.03、1.05 eV。结合染料禁带宽度计算不同 $\mathrm{pH}$ 的黑枸杞染料 LUMO 和 HOMO 值, 相关染料的 氧化还原电位数据列于表 1 。图 3 表示染料电子能 级跃迁, 从图中可知不同 $\mathrm{pH}$ 的黑枸杞染料 LUMO 能级均高于 $\mathrm{TiO}_{2}$ 导带能级 $\left(E_{\mathrm{CB}}=-4.0 \mathrm{eV}\right)$, 因此染料 分子均能将电子注入到的 $\mathrm{TiO}_{2}$ 导带中, 同时 $\mathrm{HOMO}$ 能级均低于电解质的氧化还原电位 $(E=-4.8 \mathrm{eV})$, 氧 化的染料更容易得电子而再生, 所以不同 $\mathrm{pH}$
的黑枸杞染料均能满足 DSSCs 的要求。 HOMO 能 级与 $\mathrm{I}^{-} / \mathrm{I}_{3}^{-}$的氧化还原电位差值决定了染料再生驱动 力大小, 染料再生驱动力过小则会降低电子的传递 速度, 并且加快一些副反应的反应速率。染料 $\mathrm{pH}=1 、 3 、 5 、 7$ 时, 染料再生驱动力分别为 0.72 、 $0.75 、 0.63 、 0.66 \mathrm{eV}$, 当 $\mathrm{pH}=3$ 时再生驱动力最大, 具 有更正的 HOMO 能级, 从而也减小了副反应的速 率。结合紫外吸收, 本文以 $\mathrm{pH}=3$ 的黑枸杞染料为染 料敏化剂。

\section{2 对电极表征}

图 4 为不同含量 EC 的 GNs 对电极 SEM 照片, 图中显示 GNs 对电极有较好的网状结构, 有利于载 流子的传输, 其中 EC 含量为 $10 \mathrm{wt} \%$ 时的 GNs 网状 结构更完整, 缺陷较少。

图 5 为不同含量 $\mathrm{EC}$ 的 GNs 对电极 SEM 断面 照片, 其中 $\mathrm{EC}$ 含量为 $10 \mathrm{wt} \%$ 的 GNs 厚度及断面均匀, $\mathrm{EC}$ 含量为 $5 \mathrm{wt} \%$ 的 GNs 厚度不均匀并且断面有空洞, $\mathrm{EC}$ 含量为 $15 \mathrm{wt} \%$ 的 GNs 厚度均匀但是断面有空洞。

用电化学阻抗研究电子在对电极上的传递过程, 采用两个相同对电极组成的对称电池进行阻抗谱的 测试, 结果如图 6 所示, 其中 $R_{\mathrm{s}}$ 为串联电阻, $R_{\mathrm{ct}}$ 为 电子在对电极中的传输电阻, 等效电路参数如表 2 所示。图中不同含量 $\mathrm{EC}$ 的 $\mathrm{GNs}$ 对电极 $R_{\mathrm{s}}$ 值与 $\mathrm{Pt}$ 对电极相近, 说明 GNs 对电极与基底 FTO 有良好的

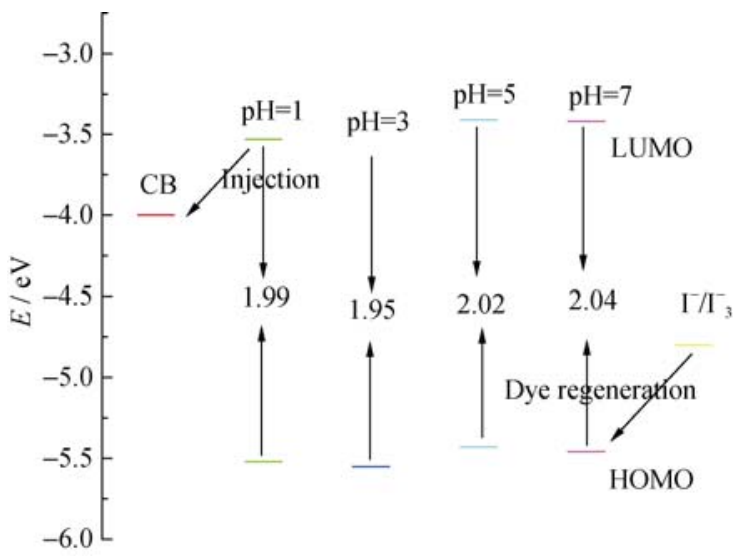

图 3 不同 $\mathrm{pH}$ 染料的能级示意图

Fig. 3 Energy level digram of sensitized with dyes under different $\mathrm{pH}$

表 1 不同 $\mathbf{p H}$ 染料的电化学参数

Table 1 Electrochemical data of pigment from Lycium ruthenicum Murray under different pH

\begin{tabular}{cccccc}
\hline Dye & $\lambda_{0} / \mathrm{nm}$ & $E_{\mathrm{g}} / \mathrm{eV}$ & $E_{\text {ox }} / \mathrm{V}$ & $\mathrm{HOMO} / \mathrm{eV}$ & $\mathrm{LUMO} / \mathrm{eV}$ \\
\hline $\mathrm{pH}=1$ & 623 & 1.99 & 1.12 & -5.52 & -3.53 \\
$\mathrm{pH}=3$ & 636 & 1.95 & 1.15 & -5.55 & -3.60 \\
$\mathrm{pH}=5$ & 614 & 2.02 & 1.03 & -5.43 & -3.41 \\
$\mathrm{pH}=7$ & 608 & 2.04 & 1.05 & -5.46 & -3.42 \\
\hline
\end{tabular}



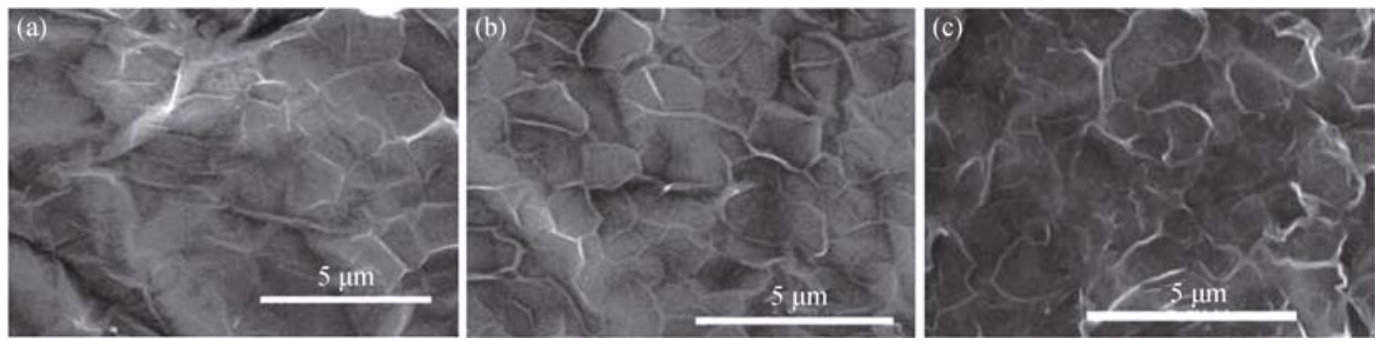

图 4 不同对电极的 SEM 照片

Fig. 4 SEM images of different counter electrodes

(a) GNs/EC(5wt\%); (b) GNs/EC(10wt\%); (c) GNs/EC(15wt\%)
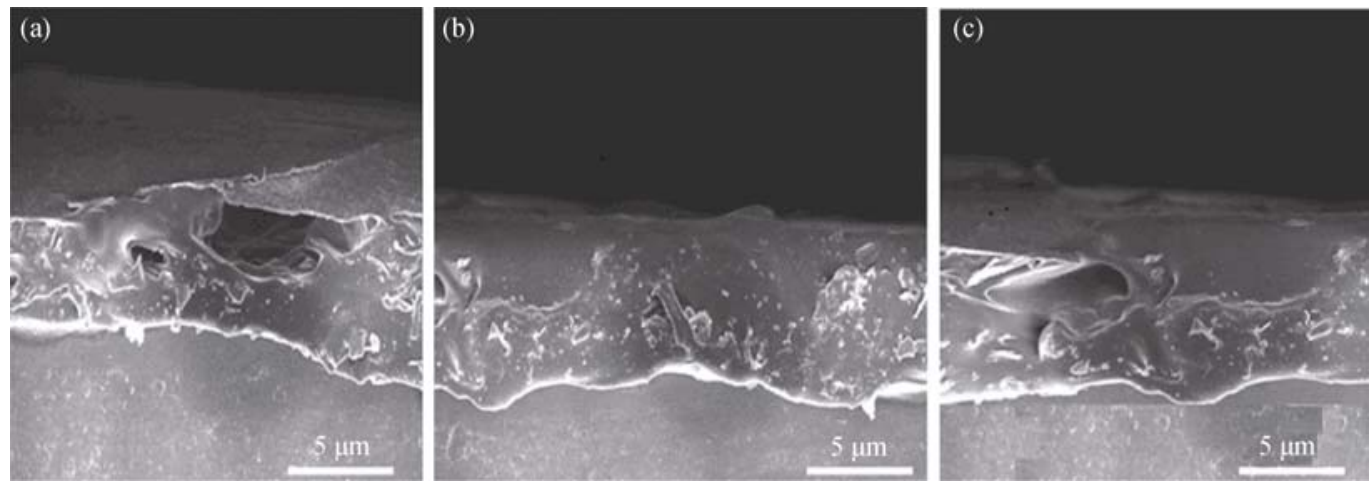

图 5 不同对电极的 SEM 断面照片

Fig. 5 Section SEM images of different counter electrodes

(a) GNs/EC(5wt\%); (b) GNs/EC(10wt\%); (c) GNs/EC(15wt\%)

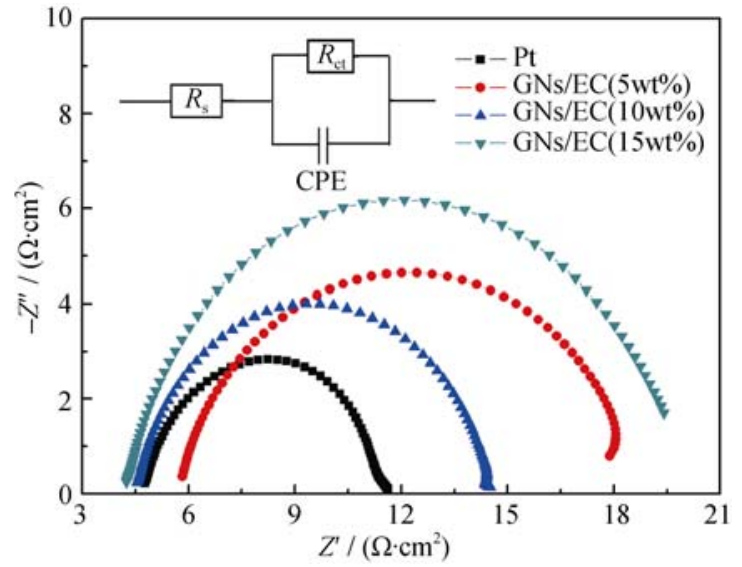

图 6 不同对电极的电化学阻抗谱

Fig. 6 Electrochemical impedance spectra of different counter electrodes

表 2 不同对电极 EIS 参数

Table 2 EIS parameters of different counter electrodes

\begin{tabular}{cccc}
\hline Sample & $R_{\mathrm{s}} / \Omega$ & $R_{\mathrm{ct}} / \Omega$ & $E_{\mathrm{p}} / \mathrm{V}$ \\
\hline $\mathrm{Pt}$ & 4.51 & 7.64 & 1.03 \\
$\mathrm{GNs} / \mathrm{EC}(5 \mathrm{wt} \%)$ & 5.53 & 11.27 & 1.08 \\
$\mathrm{GNs} / \mathrm{EC}(10 \mathrm{wt} \%)$ & 4.52 & 9.12 & 1.05 \\
$\mathrm{GNs} / \mathrm{EC}(15 \mathrm{wt} \%)$ & 4.36 & 12.95 & 1.12 \\
\hline
\end{tabular}

粘结性能, 其中 $\mathrm{EC}$ 含量为 $10 \mathrm{wt} \%$ 的 $\mathrm{GNs}$ 对电极与 $\mathrm{Pt}$ 对电极 $R_{\mathrm{s}}$ 值最为接近, 粘结性最佳。其次, $\mathrm{Pt}$ 对
电极圆弧半径最小, 表明催化活性能最好, 这与 $\mathrm{Pt}$ 本身有着极强的催化效应和紧密的 Pt 膜结构有关。 $\mathrm{EC}$ 含量为 $5 \mathrm{wt} \% 、 10 \mathrm{wt} \% 、 15 \mathrm{wt} \%$ 的 GNs 对电极 $R_{\mathrm{ct}}$ 分别为 $11.27 、 9.12 、 12.95 \Omega$, 当 $\mathrm{EC}$ 含量为 $10 \mathrm{wt} \%$ 时 $\mathrm{GNs}$ 对电极 $R_{\mathrm{ct}}$ 较小, 有着良好催化活性。

图 7 为 $\mathrm{Pt}$ 对电极和不同 $\mathrm{EC}$ 含量的 GNs 对电极 的循环伏安曲线, 测试以铂丝为工作电极, 铂片为 对电极, $\mathrm{Ag} / \mathrm{Ag}^{+}$电极为参比电极, $10 \mathrm{mmol} / \mathrm{L} \mathrm{LiI}+$ $0.1 \mathrm{mmol} / \mathrm{L} \mathrm{I}_{2}+0.1 \mathrm{~mol} / \mathrm{L} \mathrm{LiCIO}_{4}$ 乙腈溶液为电解液。 通过循环伏安电流与电位的测定，分析对电极的催 化性能。图中 $\mathrm{EC}$ 含量为 $5 \mathrm{wt} \% 、 10 \mathrm{wt} \% 、 15 \mathrm{wt} \%$ 的 GNs 对电极与 Pt 对电极的循环曲线类似, 并且有两 对氧化还原峰，电势更负的峰对应还原反应如式(1) 所示, 电势更正的峰对应氧化反应如式(2)所示, 说 明不同含量 $\mathrm{EC}$ 制备的 GNs 对电极都有良好的催化性 能。氧化还原峰间距 $E_{\mathrm{p}}$ 值依次为 $1.03 、 1.08 、 1.05$ 、 $1.12 \mathrm{~V}, 10 \mathrm{wt} \% \mathrm{EC}$ 含量的 $\mathrm{GNs}$ 对电极 $E_{\mathrm{p}}$ 值与 $\mathrm{Pt}$ 对电 极接近, 并且 $\mathrm{EC}$ 含量为 $10 \mathrm{wt} \%$ 的 GNs 对电极在正 电位有较大的电流密度, 说明该电极对 $\mathrm{I}^{-} / \mathrm{I}_{3}{ }^{-}$的氧化 还原电催化活性最好。

$$
\begin{array}{r}
\mathrm{I}_{3}{ }^{-}+2 \mathrm{e}^{-} \rightarrow 3 \mathrm{I}_{3}{ }^{-} \\
2 \mathrm{I}_{3}{ }^{-}-2 \mathrm{e}^{-} \rightarrow 3 \mathrm{I}_{2}
\end{array}
$$




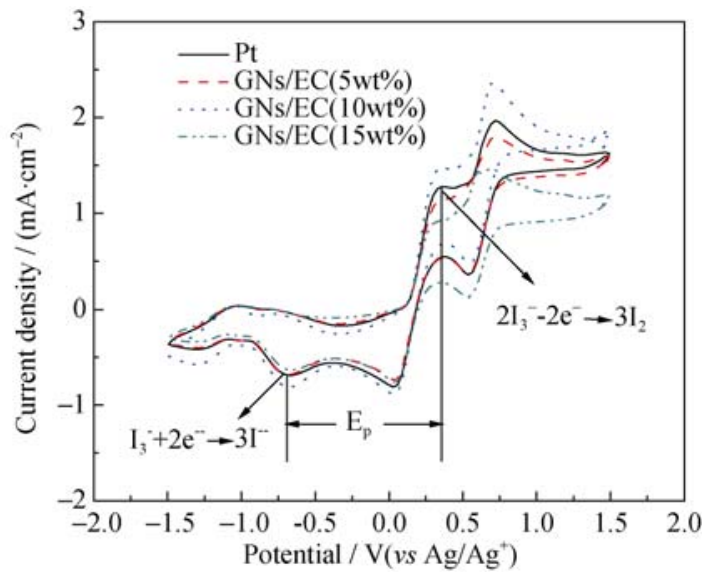

图 7 不同对电极的循环伏安曲线

Fig. 7 Cyclic voltammogram curves of different counter electrodes

通过对称电池结构进行塔菲尔极化曲线的测试, 进一步分析对电极电催化活性。从图 8 所示塔菲尔 极化曲线的陡峭趋势来判定对电极电催化性能的大 小，曲线越陡电催化活性越大。并且用交换电流密 度 $\left(J_{0}\right)$ 与极限扩散电流密度 $\left(J_{\mathrm{lim}}\right)$ 来评判对电极材料 对 $\mathrm{I}^{-}$的还原能力和电解液中 $\mathrm{I}_{3}{ }^{-}$的扩散能力, 从图 8 看出 $\mathrm{Pt}$ 对电极的电催化性最好, 在 $\mathrm{GNs}$ 对电极中, $\mathrm{EC}$ 含量为 $10 \mathrm{wt} \%$ 的 $\mathrm{GNs}$ 对电极曲线最陡, $J_{0}$ 和 $J_{\mathrm{lim}}$ 最大, 对 $\mathrm{I}^{-}$的还原电催化活性最大, 并且 $\mathrm{I}_{3}{ }^{-}$的扩散 速率最快, 由公式(3)得出 $J_{0}$ 随 $R_{\mathrm{ct}}$ 的增大而减小, 这 与电化学阻抗分析的结果一致。

$$
J_{0}=\mathrm{R} T / n \mathrm{~F} R_{\mathrm{ct}}
$$

式中 $J_{0}$ 为交换电流密度, $\mathrm{R}$ 为气体摩尔常数, $T$ 为热 力学温度, $n$ 为电子数, $\mathrm{F}$ 为法拉第常数, $R_{\mathrm{ct}}$ 为传输 电阻。

\subsection{DSSCs 测试}

图 9 为 $\mathrm{pH}=3$ 的黑枸杞染料与不同对电极组装 电池测试得到的 $J-V$ 曲线, 相关电池性能参数如表 3

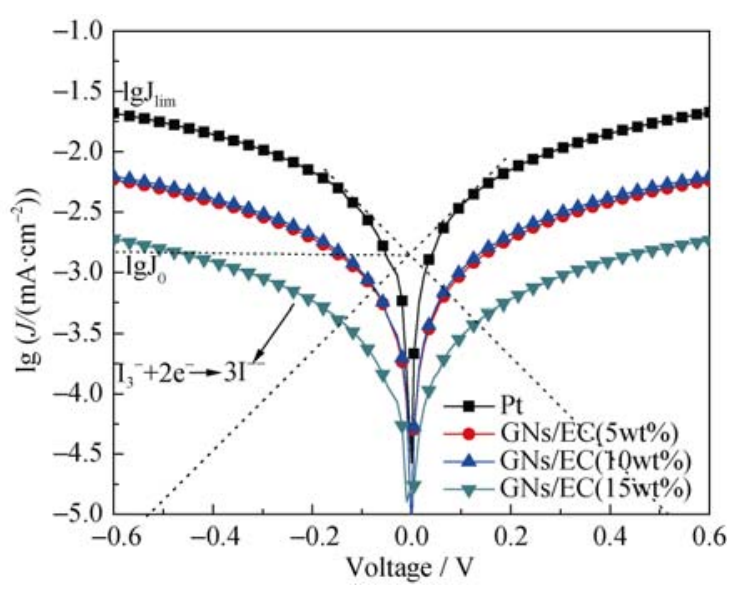

图 8 不同对电极的塔菲尔极化曲线

Fig. 8 Tafel curves of different counter electrodes

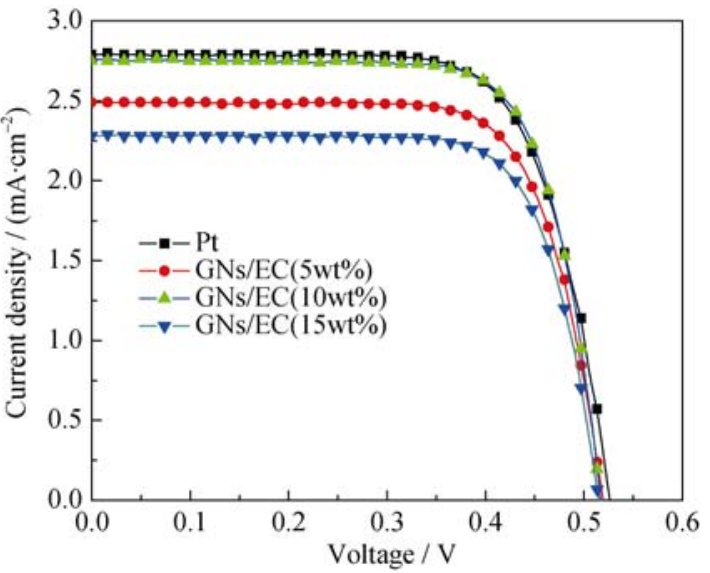

图 9 不同对电极下黑枸杞染料的电流-电压曲线

Fig. 9 Current-potential $(J-V)$ curve of different counter electrodes using pigment from Lycium ruthenicum Murray as sensitizer

表 3 不同对电极下黑枸杞染料的光电性能参数

Table 3 Parameters of DSSCs based on different counter electrodes using pigment from Lycium ruthenicum Murray as sensitizer

\begin{tabular}{ccccc}
\hline Dye & $J_{\mathrm{SC}} /\left(\mathrm{mAcm}^{-2}\right)$ & $V_{\mathrm{oc}} / \mathrm{V}$ & $F F$ & $\eta / \%$ \\
\hline $\mathrm{Pt}$ & 2.74 & 0.532 & 0.68 & 0.99 \\
$\mathrm{GNs} / \mathrm{EC}(5 \mathrm{wt} \%)$ & 2.49 & 0.530 & 0.62 & 0.82 \\
$\mathrm{GNs} / \mathrm{EC}(10 \mathrm{wt} \%)$ & 2.72 & 0.529 & 0.64 & 0.92 \\
$\mathrm{GNs} / \mathrm{EC}(15 \mathrm{wt} \%)$ & 2.26 & 0.528 & 0.66 & 0.79 \\
\hline
\end{tabular}

所示，从中看出当黑枸杞染料与 $10 \mathrm{wt} \% \mathrm{EC}$ 的 $\mathrm{GNs}$ 对电极组装电池后, 电池的光电流密度 $J_{\mathrm{sc}}$ 、开路电 压 $V_{\mathrm{oc}}$ 、光电转换效率 $\eta$ 与 $\mathrm{Pt}$ 对电极相差不大，电 池的光电转换效率最大, 为 $0.92 \%$, 分别是 $\mathrm{GNs} / \mathrm{EC}$ $(5 \mathrm{wt} \%)$ 和 $\mathrm{GNs} / \mathrm{EC}(15 \mathrm{wt} \%)$ 的 $1.12 、 1.16$ 倍。

\section{3 结论}

从高原黑枸杞中提取染料, $\mathrm{pH}=3$ 时染料光电化 学性能最佳。制备不同 EC 含量的 GNs 对电极, 当 $\mathrm{EC}$ 含量为 $10 \mathrm{wt} \%$ 时, 电极电催化性能接近 $\mathrm{Pt}$ 对电 极。将 $\mathrm{pH}=3$ 的黑枸杞染料与 GNs 对电极结合组装 电池后进行光伏性能测试, 结果表明, EC 含量为 $10 \mathrm{wt} \%$ 的 GNs 对电极光电转换效率达到 $\mathrm{Pt}$ 对电极的 93\%。这些研究为不同对电极材料在天然染料敏化 太阳能中的应用提供了新的思路。

\section{参考文献:}

[1] SIMON M, ASWANII Y, PENG G, et al. Dye-sensitized solar cells with $13 \%$ efficiency achieved through the molecular engineering of porphyrin sensitizers. Nature Chemistry, 2014, 6: 242-247.

[2] GRATZELL M. The advent of mesoscopici njection solar cells. 
Res Appl, 2006, 14: 429-442.

[3] KUMARA N, EKANAYAKE P, LIM A, et al. Layered co-sensitization for enhancement of conversion efficiency of natural dye sensitized solar cells. Journal of Alloys and Compounds, 2013, 581: 186-191.

[4] GIUSEPE C, CRISTINA C, CRUP I C, et al. Absorption spectra and photovoltaic characterization of chorophyllins as sensitizers for dye-sensitized solar cells. Spectrochmica Acta Part A:Molecular and Biomolecular Spectroscopy, 2014, 132: 477-484.

[5] ANDRES P, NEYDE Y M I. Clean and renewable energy from dye-sengsitized solar cells using fruit extracts. RIO 3-World Climate and Energy Event, 2003, 12(1-5): 91-96.

[6] PAQK K, KIM T, PARK J, et al. Adsorption characteristics of gardenia yellow as natural photosensitizer for dye-sensitized solar cells. Dyes and Pigments, 2013, 96: 595-601.

[7] YANG G J, WANG S R, ZHANG Y C, et al. Effect of pH values on performance of trollius chinensis pigment sensitized solar sells. Acta Phys. Chim. Sin., 2013, 29 (3): 539.

[8] PENG Q, BAI X F, DU Y G, et al. Research progress of polysacharides from Lycium rathenicam murrdye. Acad. Period Farm Prod. Proces., 2010, 12: 77-79.

[9] HANCH A, GEORG A. Diffusion in the electrolyte and chargetransfer reaction at the platinum electrode in dye-sensitized solar cells. Electrochion Acta, 2011, 46(4): 3457-3466.

[10] OLSEN E, HAGEN, LINDQUIST S E. Dissolution of platinum in methoxy propionitrile containing LiI// $\mathrm{I}_{2}$. Solar Energy Mater Solar Cells, 2000, 63(3): 267-273.

[11] XIANG Q, YU J, JARONIEC M. Graphene-based semiconductor photocatalysts. Chemical Society Review, 2012, 41(2): 782-796.

[12] CI S Q, WU Y M, ZOU J P, et al. Nitroger-doped graphene nanosheets as high efficient catalysts for oxygen reduction reaction. Chinese Science Bulletion, 2012, 57(22): 3067-3070.

[13] CHOI H, KIM H, HWANG S, et al. Dye-sensitized solar cells using graphene-based carbon nano composite as counter electrode. Solar Energy Materials and Solar Cells, 2011, 95(1): 323-325.

[14] MIAO X H, PAN K, PAN Q J, et al. Highly crystalline graphene/carbon black composite counter electrodes with controllable content: synthesis, characterization and application in dye- sensitized solar cells. Electrochion Acta, 2011, 96: 155-163.

[15] DAVIES A, YU A P. Material advancements in supercapacitors: from activated carbon to carbon nanotube and graphene. The Canadian Journal of Chemical Enineering, 2011, 89(6): $1342-1357$.

[16] LIU Y, ZHAO Y L, GAO Z F, et al. Facile synthesis and supercapacitor properties of graphene nanoshheets. Journal of Inorganic Materials, 2013, 28(6): 611-615. 